
\title{
A survey of recommended practices made by in the United States and Canada
}

\author{
G. D. Fike, ${ }^{*}$ J. C. Simroth, † D. U. Thomson, † E. F. Schwandt,† R. Spare, $\ddagger$ and A. J. Tarpoff§ ${ }^{1}$ \\ ${ }^{*}$ Red Angus Association of America, Denton, TX 76207; †Department of Diagnostic Medicine/Pathobiology, \\ College of Veterinary Medicine, Kansas State University, Manhattan 66506; $\ddagger$ Ashland Veterinary Center Inc., \\ Ashland, KS 67831; and §Department of Animal Sciences and Industry, Kansas State University, Manhattan \\ 66506
}

\section{ABSTRACT}

Practicing veterinarians $(\mathrm{n}=148)$ who service commercial beef cow-calf herds responded to a survey describing general recommendations made to their clients in terms of vaccine protocol, health, and production practices. Responding veterinarians represented 35 states in the United States and 3 provinces in Canada. More than 50\% of responding veterinarians devote over $50 \%$ of their practice to service commercial cow-calf producers. The largest group $(33 \%)$ of veterinarians have been in practice for over $30 \mathrm{yr}$. Thirty-nine percent of responding veterinarians serviced more than 10,000 cows. Genetic advice is provided by $54 \%$ of practicing veterinarians. When vaccinating at branding, the most common recommended vaccines are clostridial $(96 \%)$, infectious bovine rhinotracheitis (IBR; 94\%), bovine respiratory syncytial virus (BRSV; 91\%), parainfluenza-3 (PI-3; 90\%), and bovine viral diarrhea (BVD) Types 1 and 2 (78 and 77\%, respectively). When vaccinating before weaning, the most common recommended vaccines are IBR (99\%), BRSV (98\%), BVD Types 1 and 2 (96\%), PI-3 (93\%), clostridial (77\%), and Mannheimia haemolytica (77\%). When vaccinating after weaning, the most common recommended vaccines are BVD Type 2 (97\%), IBR (97\%), BVD Type 1 (96\%), BRSV (96\%), and PI-3 (91\%). Over $60 \%$ of responding veterinarians recommended that the last preventative vaccine should be administered to cattle 7 to $21 \mathrm{~d}$ before shipping. The largest number of respondents $(38 \%)$ recommended that the earliest age their clients should wean their calves is 90 to $120 \mathrm{~d}$. Castrating bull calves at an age of 0 to $7 \mathrm{~d}$ was recommended by $34 \%$ of respondents. Calf nutrition is considered as extremely important during a preconditioning program by $82 \%$ of responding veterinarians.

Key words: beef, cow-calf, survey, veterinary practitioner

The authors declare no conflict of interest.

${ }^{1}$ Corresponding author: tarpoff@ksu.edu

\section{INTRODUCTION}

Veterinary practitioners provide constant advice and recommendations to beef cow-calf operations across the United States and Canada regarding health, well-being, and production practices to gain satisfactory health status and optimum herd performance. Summarizing and reporting these recommendations provides valuable feedback to understand how best management practices are applied at the beef cow-calf herd level. These recommendations, over time, have been developed by academic researchers, practicing veterinarians, consulting veterinarians, and other animal health professionals. Currently, there are several published resources in the literature that provide recommendations made to feedlot managers by consulting veterinarians regarding animal health and well-being (Terrell et al., 2011; Terrell et al., 2014; Lee et al., 2015). In addition, similar publications exist for recommendations made by consulting nutritionists for nutritional recommendations in feedlot operations (Galyean, 1996; Galyean and Gleghorn, 2001; Vasconcelos and Galyean, 2007; Samuelson et al., 2016). Although there is limited and outdated published data (Sanderson et al., 2000) that provide a description of health and production practices employed by cow-calf producers, there is no published data that describe recommendations made by veterinary practitioners to cow-calf operations. Thus, the objective of this survey was to obtain descriptive data to describe recommended practices made by veterinary practitioners who service clients with commercial beef cow-calf operations in the United States and Canada in terms of vaccine protocols, health practices, and production practices.

\section{MATERIALS AND METHODS}

Institutional Animal Care and Use Committee approval was not required for this study because no animals were used. Approval to conduct this survey was granted by the Institutional Review Board at Kansas State University (IRB \#8423). 


\section{Survey Participants}

Veterinary practitioners were contacted for participation in this study based on their individual participation in professional veterinary organizations. A total of 1,200 veterinarians were randomly contacted through the Academy of Veterinary Consultants and American Association of Bovine Practitioners respective email listservs. Veterinarians were sent an individual electronic invitation requesting their participation in the study. A total of 148 veterinarians completed this survey.

\section{Data Collection}

The survey was conducted during the month of September 2016. Data were collected using Kansas State University's web-based survey software Qualtrics Online (Qualtrics 2015, Version 2417833, Provo, UT). Invited veterinarians received a URL to access the survey via an email invitation. There was no information requested in the survey that identified individual veterinary practitioners, making responses completely anonymous. Participating veterinarians had 4 wk to access and complete the survey after receiving the original email invitation with the URL. An email reminder to complete the survey was sent to participants once at 2 wk after the survey was available to them.

The survey was composed of 42 questions covering areas of vaccine protocol, health practices, and production practices for beef cow-calf operations. Several questions gave the respondent the option to choose "Other" as an answer and type their response in a blank space. These responses were also included in the analysis.

\section{Data Analysis}

Response data collected from this survey were downloaded from the web-based survey software into a Microsoft Excel (Microsoft, Redmond, WA) spreadsheet for summarization and descriptive analysis. Graphs, tables, number of respondents per question, frequency of responses per question, means, minimum values, and maximum values were calculated for all questions using Microsoft Excel. Not all respondents answered all questions; therefore, the number of total responses to each individual question was expressed as a percentage of the number of answers to that question out of total survey responses.

\section{RESULTS AND DISCUSSION}

The United States produced a total of 11.5 million tonnes of beef during 2016, making it the number one beef producer in the world (USDA, 2017a). Beef cattle operations represented a total of 93.6 million cattle as of January 1, 2017, in the United States (USDA, 2017b). In 2016 the calf crop in the United States was estimated at 35.1 million cattle, and all cows and heifers that have calved represented 40.6 million cattle according to the 2016 USDA Cattle report (USDA, 2017c). Currently, there are less than 32 million head of beef cows widely dispersed throughout the United States on over 720,000 farms and ranches (USDA, 2017c).

The cow-calf operation is considered the first stage of the beef production process, and it takes slightly over 2 yr from the time cows and heifers are bred until their offspring are ready for slaughter (Comerford et al., 2013). As of 2012, there were almost 728,000 cow-calf operators in the United States according to the most recent Census of Agriculture (USDA, 2014). Although cow-calf operations are spread across the United States, the top 25 cow-calf operations during 2015, ranked by number of cows, were located in Florida, Texas, Wyoming, California, Hawaii, Idaho, Kansas, Missouri, and New Mexico (NCBA, 2015). Texas was the state with the greatest number of beef cows and calves under $205 \mathrm{~kg}$ and the largest calf crop (4.5, 2.0, and 4.3 million, respectively; USDA, 2017c) for 2016; however, 9 out of the top 25 cow-calf operators in the country were in Florida during 2015 (NCBA, 2015).

An increase in preventative healthcare and management measures among beef cow-calf operations in the United States has been the result of an integrated proposal that advocates to improve health, performance, and profitability for the beef industry. These recommended programs, commonly referred to as preconditioning or backgrounding, focus on optimal cow herd nutrition and health, early castration and dehorning, anthelmintic treatment, proper and timely vaccinations for calves, and the weaning of calves 30 to $45 \mathrm{~d}$ before shipping (Kirkpatrick et al., 2008). Preventative programs that reduce compounded stress have been shown to reduce incidence of bovine respiratory disease (BRD) in the feedlot (Cole et al., 1979; Roeber et al., 2001) and improve ADG in the preconditioning period (Bolte et al., 2009) and the finishing phase (Peterson et al., 1989).

\section{Demographic Information}

Table 1 provides general information and demographics of participating veterinary practitioners including states where they practice, proportion of their practice dedicated to cow-calf producers, years in practice, and number of beef cows serviced. A total of 148 veterinary practitioners responded to the survey, with most participants providing a response to the majority of questions. Responding veterinarians represented 35 states in the United States and 3 provinces in Canada. In the United States, $11 \%$ of veterinarians practiced in Kansas; $10 \%$ in Nebraska and Iowa; $6 \%$ in Oklahoma and South Dakota; and 5\% in Missouri, Minnesota, and Texas (the remaining states represented less than $5 \%$ of total responses). In Canada, veterinarians practiced in Alberta, Ontario, and Quebec, but these represented less than $5 \%$ of the total response. 
Over $50 \%$ of responding veterinarians devoted more than $50 \%$ of their practice to service commercial cow-calf producers (Table 1). The largest group (33\%) of veterinarians had been in practice for over $30 \mathrm{yr}$. However, $26 \%$ of responding veterinarians had been in practice for only 0 to 5 yr. Similarly, Coetzee et al. (2010) reported that almost half of veterinarians $(45.5 \%)$ participating in a castration method survey had been in practice for over $20 \mathrm{yr}$, and the second largest group of participating veterinarians $(15 \%)$ had been in practice only 1 to 5 yr. More than 10,000 cows were serviced by $39 \%$ of these veterinarians' practices, whereas $25 \%$ of veterinarians serviced 5,000 to 10,000 cows each.

\section{Vaccination Protocols}

The most important component of a beef cattle herd health program is the use of vaccines as a management practice to avoid the spread of infectious diseases within the herd. Vaccinating cattle is a relatively common practice among cow-calf operations; however, not all United States cow-calf operations vaccinate their cattle, leaving

Table 1. Descriptive data about general information and demographics of responding veterinarians $(n=178)$ to a survey of recommended practices to cow-calf operations in the United States and Canada

\begin{tabular}{|c|c|c|}
\hline Item & $\begin{array}{l}\text { Responses } \\
\text { (no.) }\end{array}$ & $\begin{array}{l}\text { Responses } \\
(\%)\end{array}$ \\
\hline \multicolumn{3}{|l|}{ States represented by responding veterinarians' practice $(n=136 ; 93 \% \text { response rate })^{1,2}$} \\
\hline Kansas & 20 & 11.0 \\
\hline Nebraska & 19 & 10.4 \\
\hline lowa & 18 & 9.9 \\
\hline Oklahoma, South Dakota & 11 & 12.0 \\
\hline Missouri & 10 & 5.5 \\
\hline Minnesota, Texas & 9 & 9.8 \\
\hline Georgia & 7 & 3.8 \\
\hline Montana & 5 & 2.7 \\
\hline Alabama, Colorado, Illinois, Oregon, Virginia, Wisconsin & 4 & 13.2 \\
\hline Alberta, ${ }^{3}$ Arkansas, Florida, Idaho, North Carolina, North Dakota & 3 & 9.9 \\
\hline Arizona, Kentucky, Ohio, South Carolina, West Virginia & 2 & 5.5 \\
\hline $\begin{array}{l}\text { Hawaii, Indiana, Louisiana, Michigan, Mississippi, Ontario, }{ }^{3} \text { Pennsylvania, Quebec, }{ }^{3} \\
\text { Tennessee, Utah, Wyoming }\end{array}$ & 1 & 6.0 \\
\hline \multicolumn{3}{|l|}{$\begin{array}{l}\text { Proportion of veterinarians' practice that is devoted to cow-calf producers ( } n=146 ; 99 \% \\
\text { response rate) }\end{array}$} \\
\hline$<10 \%$ & 13 & 9 \\
\hline 11 to $25 \%$ & 16 & 11 \\
\hline 26 to $50 \%$ & 41 & 28 \\
\hline 51 to $75 \%$ & 46 & 32 \\
\hline$>76 \%$ & 30 & 21 \\
\hline \multicolumn{3}{|l|}{ Number of years that veterinarians have been in practice $(n=147 ; 100 \%$ response rate) } \\
\hline 0 to 5 & 38 & 26 \\
\hline 6 to 10 & 20 & 14 \\
\hline 11 to 15 & 13 & 9 \\
\hline 16 to 20 & 13 & 9 \\
\hline 21 to 25 & 2 & 1 \\
\hline 26 to 30 & 12 & 8 \\
\hline$>30$ & 49 & 33 \\
\hline \multicolumn{3}{|l|}{ Number of beef cows serviced by practicing veterinarians $(n=147 ; 100 \%$ response rate) } \\
\hline$<1,000$ & 15 & 10 \\
\hline 1,001 to 2,500 & 17 & 12 \\
\hline 2,501 to 5,000 & 20 & 14 \\
\hline 5,001 to 10,000 & 37 & 25 \\
\hline$>10,000$ & 58 & 39 \\
\hline
\end{tabular}

${ }^{1}$ The number of responses corresponds to the number of veterinarians that practice in each state.

${ }^{2}$ Percentage of total responses $(n=136)$; for rows with more than one state listed, the percentage shown reflects the sum of percentages from each individual state.

${ }^{3}$ Canada. 
a significant portion of the beef cattle population susceptible to multiple preventable diseases (USDA, 2010). According to the USDA (2010), during 2007 only $68.9 \%$ of cow-calf operations vaccinated cattle. However, the 2016 CattleFax Cow-Calf Survey reported that $93 \%$ of surveyed operations in the United States have in place a vaccination plan for cattle, and Waldner et al. (2013) reported that most (85.3\%) Canadian cow-calf producers vaccinate their calves before moving the herd to pasture.

When vaccinating calves for the first time at branding (Table 2), the most common recommended vaccines were clostridial (96\%), infectious bovine rhinotracheitis (IBR; 94\%), bovine respiratory syncytial virus (BRSV; $91 \%$ ), parainfluenza-3 (PI-3; 90\%), and bovine viral diarrhea (BVD) Type 1 and 2 (78 and 77\%, respectively). For type of vaccine used at this time, $80 \%$ of veterinarians recommended modified live virus (MLV) vaccines and $12 \%$ recommended killed vaccines at this time. Another vaccine used by veterinarians but not listed was Moraxella bovoculi $(2 \%)$.

When vaccinating calves for the first time before weaning (Table 3), the most common recommended vaccines were IBR (99\%), BRSV (98\%), BVD Types 1 and 2 (96\%), PI-3 (93\%), clostridial (77\%), and Mannheimia haemolytica $(77 \%)$. Ninety percent of veterinarians recommended MLV vaccines and 10\% recommended killed vaccines at this time. Brucellosis (1\%) was another vaccine that was not listed and that was used by veterinarians before weaning.
When vaccinating calves for the first time after weaning (Table 4), the most common recommended vaccines were BVD Type 2 (97\%), IBR (97\%), BVD Type 1 (96\%), BRSV (96\%), and PI-3 (91\%). For this period of time $93 \%$ of veterinarians recommended MLV vaccines and $7 \%$ recommended killed vaccines. Other vaccines used by veterinarians but that were not listed included brucellosis (1\%), Brucella abortus strain RB-51 (1\%), and vibriosisleptospirosis combo (1\%).

Results from this survey regarding recommended antigens to vaccinate calves are similar to USDA's Beef 2007-08 report (USDA, 2010), where over $50 \%$ of cowcalf operations administered a clostridial vaccine to calves before weaning, over $30 \%$ of operations administered IBR and BVD vaccines before weaning, and over $25 \%$ vaccinated calves for PI-3 and BRSV. Survey results are also in agreement with recommendations made by Comerford et al. (2013), whom suggested that any health program should include vaccination for IBR, PI-3, BRSV, BVD, Haemophilus somnus, leptospirosis, and clostridial diseases. Similarly, Waldner et al. (2013) reported that the most commonly used vaccines by Canadian cow-calf producers to vaccinate calves were clostridial $(84.6 \%)$ and BVD and IBR (55.6\%). Furthermore, Woolums et al. (2014) reported that $87 \%$ of respondents to a survey of veterinarians that deal with nursing beef calf respiratory disease recommend a routine administration of respiratory vaccines to beef calves. However, USDA (2010) reported that during $2007,60.6 \%$ of beef cow-calf operations did not vaccinate

Table 2. Descriptive data about vaccination, antigens, and type of vaccine recommended by practicing cow-calf veterinarians for calves at branding time in the United States and Canada

\begin{tabular}{|c|c|c|}
\hline Item & $\begin{array}{l}\text { Responses } \\
\text { (no.) }\end{array}$ & $\begin{array}{l}\text { Responses } \\
(\%)\end{array}$ \\
\hline \multicolumn{3}{|c|}{$\begin{array}{l}\text { Antigens recommended for vaccinating calves for the first time at branding ( } n=137 ; 93 \% \\
\text { response rate) }\end{array}$} \\
\hline Clostridial & 131 & 96 \\
\hline Infectious bovine rhinotracheitis & 129 & 94 \\
\hline Bovine respiratory syncytial virus & 125 & 91 \\
\hline Parainfluenza-3 & 123 & 90 \\
\hline Bovine viral diarrhea, Type 1 & 107 & 78 \\
\hline Bovine viral diarrhea, Type 2 & 105 & 77 \\
\hline Mannheimia haemolytica & 62 & 45 \\
\hline Moraxella bovis & 43 & 31 \\
\hline Pasteurella multocida & 36 & 26 \\
\hline Histophilus somni & 25 & 18 \\
\hline Leptospirosis & 7 & 5 \\
\hline Others not listed ${ }^{1}$ & 7 & 5 \\
\hline Mycoplasmal pneumonia & 2 & 1 \\
\hline Vibriosis & 1 & 1 \\
\hline \multicolumn{3}{|c|}{ Vaccine type recommended at branding time $(n=137 ; 93 \%$ response rate $)$} \\
\hline Modified live (MLV) & 121 & 88 \\
\hline Killed & 16 & 12 \\
\hline
\end{tabular}

${ }^{1}$ Moraxella bovoculi, autogenous Moraxella bovoculi, castrate or dehorn. 
Table 3. Descriptive data about vaccination, antigens, and type of vaccine recommended by practicing cow-calf veterinarians for calves before weaning in the United States and Canada

\begin{tabular}{|c|c|c|}
\hline Item & $\begin{array}{c}\text { Responses } \\
\text { (no.) }\end{array}$ & $\begin{array}{c}\text { Responses } \\
(\%)\end{array}$ \\
\hline \multicolumn{3}{|c|}{$\begin{array}{l}\text { Antigens recommended for vaccinating calves for the first time before weaning }(n=139 \text {; } \\
95 \% \text { response rate) }\end{array}$} \\
\hline Infectious bovine rhinotracheitis & 137 & 99 \\
\hline Bovine respiratory syncytial virus & 136 & 98 \\
\hline Bovine viral diarrhea, Type 1 & 134 & 96 \\
\hline Bovine viral diarrhea, Type 2 & 134 & 96 \\
\hline Parainfluenza-3 & 129 & 93 \\
\hline Clostridial & 122 & 88 \\
\hline Mannheimia haemolytica & 107 & 77 \\
\hline Histophilus somni & 62 & 45 \\
\hline Pasteurella multocida & 59 & 42 \\
\hline Leptospirosis & 14 & 10 \\
\hline Moraxella bovis & 13 & 9 \\
\hline Others not listed ${ }^{1}$ & 5 & 4 \\
\hline Mycoplasmal pneumonia & 3 & 2 \\
\hline \multicolumn{3}{|c|}{ Vaccine type recommended before weaning $(n=141 ; 96 \%$ response rate) } \\
\hline Modified live (MLV) & 127 & 90 \\
\hline Killed & 14 & 10 \\
\hline
\end{tabular}

${ }^{1}$ Brucellosis.

calves for respiratory disease from birth until the time they were sold and over $30 \%$ of all calves were on these operations. It is very probable that these recommenda- tions are made with the aim to prevent BRD, which is the most common cause of death for all production classes of cattle and calves in the United States (Woolums et al.,

Table 4. Descriptive data about vaccination, antigens, and type of vaccine recommended by practicing cow-calf veterinarians for calves after weaning in the United States and Canada

Item

Antigens recommended for vaccinating calves for the first time after weaning $(n=120 ; 82 \%$ response rate)

Bovine viral diarrhea, Type 2

Infectious bovine rhinotracheitis

Bovine viral diarrhea, Type 1

Bovine respiratory syncytial virus

Parainfluenza-3

Clostridial

Mannheimia haemolytica

Histophilus somni

Pasteurella multocida

Leptospirosis

Moraxella bovis

Mycoplasmal pneumonia

Others not listed ${ }^{1}$

Vibriosis

Vaccine type recommended after weaning ( $n=122 ; 83 \%$ response rate)

Modified live (MLV)

Killed
Responses Responses

(no.)

\begin{tabular}{rr}
116 & 97 \\
116 & 97 \\
115 & 96 \\
115 & 96 \\
109 & 91 \\
70 & 58 \\
59 & 49 \\
44 & 37 \\
36 & 30 \\
18 & 15 \\
14 & 12 \\
4 & 3 \\
4 & 3 \\
3 & 3 \\
114 & \\
8 & 93 \\
\hline
\end{tabular}

${ }^{1}$ Brucellosis, Brucella abortus strain RB-51, vibriosis-leptospirosis combo. 
2013) and costs the beef industry millions of dollars every year on prevention, control, and death loss (Macartney et al., 2003). Radostits et al. (1994) and Woolums et al. (2014) reported that viruses isolated from calves affected with BRD included IBR, BRSV, BVD, and PI-3; bacterial pathogens also isolated included M. haemolytica, Pasteurella multocida, H. somnus, Mycoplasma bovis, and Mycoplasma dispar. Furthermore, in a survey of biosecurity practices of United States beef cow-calf producers, Sanderson et al. (2000) reported that $18 \%$ of producers vaccinated cattle against IBR, $17 \%$ vaccinated against BVD, $28 \%$ against leptospirosis, 20\% against campylobacteriosis, $42 \%$ against brucellosis (for heifers), and only $1.1 \%$ vaccinated cattle against tritrichomonosis. The observed pattern of vaccination recommended by veterinarians and performed by beef cow-calf producers across the United

Table 5. Descriptive data about vaccination protocol practices recommended by practicing cow-calf veterinarians in the United States and Canada

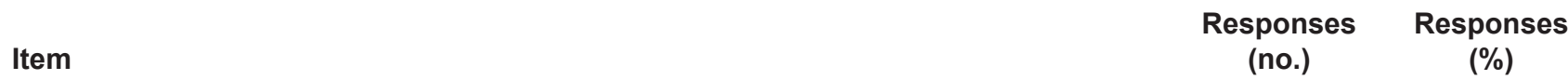

Number of days before loading or shipping that the last preventative vaccine should be administered to calves $(n=144 ; 98 \%$ response rate)

7 to 14

15 to 21

22 to 30

31 to 45

$>45$

Are bulls in the herd vaccinated at the same time as cows? ( $n=146 ; 99 \%$ response rate)

Yes

No

$\begin{array}{rr}43 & 30 \\ 45 & 31 \\ 30 & 21 \\ 21 & 15 \\ 5 & 3 \\ & \\ 116 & 79 \\ 30 & 21\end{array}$

Annual booster antigens recommended for vaccinating the female herd $(n=146 ; 99 \%$ response rate)

Infectious bovine rhinotracheitis

Bovine viral diarrhea, Type 2

Bovine viral diarrhea, Type 1

Leptospirosis

Parainfluenza-3

Bovine respiratory syncytial virus

Vibriosis

Clostridial antigens

Moraxella bovis

Others not listed ${ }^{1}$

Histophilus somni

Mannheimia haemolytica

Pasteurella multocida

Mycoplasmal pneumonia

Vaccine type recommended for annual booster vaccination of the female herd $(n=146$; $99 \%$ response rate)

Modified live (MLV)

Killed

Is a preventative scour vaccine for the breeding herd recommended as a regular part of the herd health protocol? ( $\mathrm{n}=146 ; 99 \%$ response rate)

Yes

No

Antigens recommended to use as preventative scour vaccine for the breeding herd $(\mathrm{n}=$ $120 ; 82 \%$ response rate)

Escherichia coli

Coronavirus

Bovine Rotavirus

$\begin{array}{rr}144 & 99 \\ 143 & 98 \\ 142 & 97 \\ 137 & 94 \\ 125 & 86 \\ 118 & 81 \\ 105 & 72 \\ 63 & 43 \\ 29 & 20 \\ 16 & 11 \\ 7 & 5 \\ 3 & 2 \\ 2 & 1 \\ 1 & 1 \\ & \\ & \\ 103 & 71 \\ 56 & 38 \\ & \\ 117 & 80 \\ 29 & 20 \\ & \\ & \\ 110 & 92 \\ 105 & 87 \\ 104 & \end{array}$

${ }^{1}$ Brucellosis, Salmonella, anthrax, Moraxella bovoculi, Scourguard (Zoetis Inc., Kalamazoo, MI) or Guardian (Merck Animal Health, Kenilworth, NJ), scours, E. coli, Rotavirus, Coronavirus, Clostridium perfringens, anaplasmosis, autogenous pinkeye; depends by region or need. 
States is most probably due to the fact that vaccines for BRSV, BVD, PI-3, and IBR are commercially offered in a single injection vaccine.

Responding veterinarians (30\%) recommended that the last preventative vaccine should be administered to cattle 7 to $14 \mathrm{~d}$ before being loaded, shipped, and sold; $31 \%$ of veterinarians recommended to administer it 15 to $21 \mathrm{~d}$; $21 \%$ of veterinarians 22 to $30 \mathrm{~d} ; 15 \%$ of veterinarians 31 to $45 \mathrm{~d}$; and only $3 \%$ of veterinarians recommended to administer the last preventative vaccines more than $45 \mathrm{~d}$ before loading or shipping. The majority of veterinarians $(79 \%)$ recommended vaccinating bulls at the same time that cows get vaccinated (Table 5 ).

About $20 \%$ of cow-calf operations administered annual booster vaccines for cows and bulls during 2007 (USDA, 2010). In contrast, almost all participating veterinarians $(99 \%)$ in this study recommended annual booster vaccination for the female herd. The most commonly recommended antigens administered as annual boosters to the female herd were IBR (99\%), BVD Type 2 (98\%), BVD Type 1 (97\%), leptospirosis (94\%), PI-3 (86\%), BRSV (81\%), and vibriosis (72\%). Similarly, in 2007 over $23.8 \%$ of operations gave a BVD booster vaccine to cows and $20.3 \%$ to bulls (USDA, 2010). Furthermore, $28.10 \%$ of cow-calf operations regularly vaccinate cows and bulls against BVD, $24.6 \%$ against IBR, 22.6\% against PI-3, 21.1\% against BRSV, and $19.0 \%$ against Campylobacter (USDA, 2010). When administering booster vaccines to the beef herd, USDA (2010) reported that during 2007 over $60 \%$ of cowcalf operations used killed vaccines over MLV. A divergent trend was observed in this study, with $65 \%$ of participating veterinarians recommending a MLV vaccine and $35 \%$ recommending a killed vaccine when administering annual booster vaccines to the female herd (Table 5). Other antigens administered by a minority (11\%) of veterinarians included anaplasmosis, Moraxella bovis, Escherichia coli, rotavirus, coronavirus, perfringens, Moraxella bovoculi, anthrax, salmonella, and brucellosis. The use of a preventative scour vaccine for the breeding herd was recommended by $80 \%$ of veterinarians as part of the herd vaccination protocol (Table 5), with E. coli (92\%) being the most recommended antigen for the prevention of scours, followed by Coronavirus (88\%) and bovine Rotavirus (87\%; Table 5). Similarly, Waldner et al. (2013) reported that over $40 \%$ of Canadian beef producers administered preventative scour vaccination (E. coli, Coronavirus, and Rotavirus) and over $57 \%$ of producers administered clostridial vaccines to the female herd for prevention.

\section{Health Practices}

Table 6 provides descriptive data regarding general health practices for the cow-calf herd recommended by veterinary practitioners. The most commonly recommended practices by veterinarians as part of the BVD total control program were vaccination (99\%), biosecurity $(76 \%)$, testing and removal of infected animals (62\%), and quarantine $(52 \%)$. When their clients were keeping calves past weaning for backgrounding or grazing before selling, $68 \%$ of veterinarians did not recommend to administer additional booster vaccines. Similarly, Woolums et al. (2013) reported that almost $40 \%$ of cow-calf operations that had previously vaccinated calves against BRD pathogens administered booster vaccines to calves before weaning. When banding is recommended as a castration method, regardless of the time point at which castration was performed, $97 \%$ of veterinarians also recommended that calves receive a tetanus vaccine (Table 6). This is in agreement with survey data reported by Coetzee et al. (2010), where over $50 \%$ of responding veterinarians routinely used a tetanus toxoid injection at the time of castration. Similarly, in a research trial comparing different castration methods on growth performance of beef bulls, Rust et al. (2007) administered a vaccine containing a tetanus toxoid to cattle $(\mathrm{n}=20)$ that were castrated using a high-tension elastic rubber band, with only one animal developing the disease and dying during the study.

The most commonly recommended fly control methods were herd spraying $(72 \%)$, oil-based back rubbers $(63 \%)$, and dust bags ( $52 \%$; Table 6$)$. However, veterinarians also recommended alternative methods such as pour-on products; fly tags; Permectrin CDS; feeding insect growth regulator (IGR); ear tags; LongRange; spot spray; fly baits; environmental control (predator flies); dewormers; and manure, bedding, and bale management. Similarly, over half of the cow-calf producers in the United States used a pour-on product for fly control (USDA, 2010). The use of insecticide-impregnated ear tags for fly control on cows and calves was also recommended by $76 \%$ of practicing veterinarians (Table 6).

Table 7 presents descriptive data regarding deworming practices recommended for the cow-calf herd by veterinary practitioners participating in this study. Nine out of every 10 operations in the USDA Beef 2007-08 publication reported to deworm all cattle and calves in the herd at least occasionally (USDA, 2010). Similar results are reported from this survey, where $93 \%$ of participating veterinarians recommended deworming the female herd as a regular practice. From these veterinarians who recommended deworming the female herd, $96 \%$ recommended to do it 1 to 2 times per yr. Over $80 \%$ of cow-calf operations in the United States followed this recommendation, with $5.1 \%$ of operations deworming cows less than once a yr, $38.2 \%$ of operations de-worming cows at least once a yr, and $43.5 \%$ deworming the cow herd more than once a yr (USDA, 2010). Furthermore, over $50 \%$ of veterinarians highly recommend the use of both injectable and pour on products for deworming of the female herd. Although the USDA reports that over $50 \%$ of cow-calf operations deworm calves once or more than once per year, almost $40 \%$ of them do not ever deworm calves (USDA, 2010). Deworming of calves was the second most common practice recommended by $64 \%$ of veterinarians at branding time, with injectable dewormers being the most recommended 
type by $84 \%$ of participating veterinarians for this period. The most common practice recommended by veterinarians before and after weaning was deworming of calves (76 and $81 \%$, respectively); an injectable dewormer mas the most recommended type of dewormer, recommended by $74 \%$ of veterinarians before weaning, whereas a pour-on was the most recommended $(65 \%)$ type of dewormer after weaning (Table 7).

\section{Production Practices}

Genetic advice for ranchers and producers was provided by $54 \%$ of practicing veterinarians, and the majority of veterinarians $(83 \%)$ recommended that all family members and employees should be trained on low stress handling (Table 8). Administering a growth implant was the most common practice recommended at branding by $75 \%$ veterinarians. However, the same practice was selected as the second most common one recommended by veterinarians before and after weaning (58 and 56\%, respectively). According to findings reported by USDA (2008a), 9.8\% of cow-calf operations in the United States gave calves an implant before weaning and $6.8 \%$ of operations implanted calves at weaning. The administration of probiotics to calves at branding and after weaning was only recommended by $1 \%$ of participating veterinarians (Table 8 ).
Creep feeding was recommended as a regular practice to clients by $60 \%$ of veterinarians (Table 8 ). In contrast, only $27 \%$ of cow-calf operations in the United States reported that calves had access to creep feed (USDA, 2008a). A majority (54\%) of veterinarians recommended that it would be best if calves knew how to eat from a feed bunk (bunk broke) before marketing them or shipping to a backgrounding facility or a feedlot. Thirty-six percent of these veterinarians recommended to have bunk-broke calves depending on each individual client ranch's situation, marketing strategy, or facilities (Table 8). According to data reported by the USDA (2008a,b), the most common type of individual calf identification used by almost $40 \%$ of cow-calf operations was a plastic ear tag; at least $50 \%$ of calves were identified with a plastic ear tag in these operations. The use of an ear tag for calves as an identification method, which would include sire and dam information, was recommended by $69 \%$ of veterinary practitioners in this survey. In contrast, data from the USDA (2008b) reports that only $20 \%$ of cow-calf operations used plastic ear tags on calves for herd identification, with almost $30 \%$ of all cattle and calves in the operation being ear tagged for this purpose.

The largest number of respondents (38\%) recommended that the earliest age at which their clients should wean

Table 6. Descriptive data about health practices recommended by practicing cow-calf veterinarians in the United States and Canada

Item

Responses (no.) Responses (\%)

Recommended practices as part of bovine viral diarrhea total control program $(n=147$; $100 \%$ response rate)

Vaccination

146

Biosecurity

Testing and removal ${ }^{1}$

Quarantine

Are additional booster vaccines recommended if clients keep calves past weaning? $(\mathrm{n}=$ 136; $93 \%$ response rate)

Yes

No

Is administration of a tetanus vaccine recommended to clients when banding is used as a castration method? ( $n=140 ; 95 \%$ response rate)

Yes

No

Are insecticide-impregnated ear tags recommended for fly control on cows and calves?

( $n=145 ; 99 \%$ response rate)

Yes

No

Fly control programs recommended $(n=136 ; 93 \%$ response rate)

Herd spraying

Oil-based back rubbers

Dustbags

Other

Individual animal paint ball application
43

93

136

4

110

35

98

86

71

37

14
99

76

62

52
32

68

97

3

76

24

72

63

52

27

10

${ }^{1}$ For persistently infected animals. 
their calves was 90 to $120 \mathrm{~d}$ (Table 9). However, the last Beef report publication mentions that the average age at which calves were weaned on cow-calf operations was 207 $\mathrm{d}$, with an average weaning weight of $241 \mathrm{~kg}$ for all calves (USDA, 2008b). Three-fourths of all United States operations' weaning age for calves is $<230 \mathrm{~d}$ of age (USDA, $2008 \mathrm{a}, \mathrm{b})$. The 2 most common weaning methods recommended by veterinarians were a specific number of days weaned before selling (64\%) and fence-line weaning (57\%).

Castration of bull calves intended for beef production is a commonly performed management practice in livestock operations in the United States, accounting for approximately 16 million procedures per yr (USDA, 2015). Bull calves are routinely castrated at livestock operations to decrease secondary sex characteristics, minimize aggressive behavior, facilitate management, and improve beef quality (Faulkner et al., 1992; Rust et al., 2007; Gonzalez et al., 2010). At least $77 \%$ of all bull calves were castrated on almost $60 \%$ of all cow-calf operations in the United States during 2007 (USDA, 2008a). The majority of participating veterinarians $(34 \%)$ recommended castrating bull calves at an age of 0 to $7 \mathrm{~d}$, whereas $18 \%$ of veterinarians recommended to castrate at 2 to 3 mo of age, and $16 \%$ of veterinarians recommended castrating bull calves at branding (Table 9). These recommendations are in agreement with Bretschneider (2005), who reported that, based on observations of stress response, the younger the calf when castrated, the less stressful the procedure. This is regardless of the method used, recommending that castration occur at or shortly after birth. In contrast, data from the USDA

Table 7. Descriptive data about deworming practices recommended for the cow-calf herd by practicing veterinarians in the United States and Canada

Item

Responses (no.) Responses (\%)

Is deworming of the female herd recommended? ( $n=146 ; 99 \%$ response rate)

Yes 13593

No

10

Number of times per year recommended to deworm the female herd $(n=136 ; 93 \%$

response rate)

1 to 2

$>2$

Other $^{1}$

131

3

2

Type of deworming product most highly recommended for the female herd $(n=143 ; 98 \%$

response rate)

Injectable

Pour-on

Oral or paste

Deworming practices recommended at branding time $(n=76 ; 64 \% \text { response rate })^{2}$

Injectable ${ }^{3}$

Paste or oral ${ }^{3}$

Pour-on ${ }^{3}$

Deworming practices recommended before weaning $(n=86 ; 76 \% \text { response rate })^{4}$

Injectable ${ }^{5}$

Pour-on ${ }^{5}$

Paste or oral ${ }^{5}$

Deworming practices recommended after weaning $(n=62 ; 81 \% \text { response rate })^{6}$

Pour-on ${ }^{7}$

Injectable ${ }^{7}$

Paste or oral ${ }^{7}$

${ }^{1}$ Depends on need and fecal exam; before turn out.

${ }^{2}$ For deworming practices, number and percentage of responses correspond to the total number of responses $(n=119)$ to recommended practices at branding time.

${ }^{3}$ For type of dewormer, percentages of responses are calculated from number of responses for "Deworming" ( $n=76$ ).

${ }^{4}$ For deworming practices, number and percentage of responses correspond to the total number of responses $(n=113$ ) to recommended practices before weaning.

${ }^{5}$ For type of dewormer, percentages of responses are calculated from number of responses for "Deworming" ( $n=86$ ).

${ }^{6}$ For deworming practices, number and percentage of responses correspond to the total number of responses $(n=77)$ to recommended practices before weaning.

${ }^{7}$ For type of dewormer, percentages of responses are calculated from number of responses for "Deworming" ( $\left.n=62\right)$. 
(2008a) reports that cow-calf operations in the United States castrated calves at an average age of 77 d. However, most operations $(74.5 \%)$ castrated bull calves at an age of $<93 \mathrm{~d}$, but almost $20 \%$ of operations did not castrate calves until they were over 122 d old. Several methods of castration exist (Bretschneider, 2005; Coetzee et al., 2010), each one having positive and negative attributes, but regardless of the preferred method of castration, cattle will undergo pain and stress during this procedure (Rust et al., 2007). The 2 most commonly used methods for castrating bull calves are either the surgical procedure or the rubber banding method (AVMA, 2014). Respondents were asked to rank castration methods from most to least preferred. Knife cut was selected as the preferred castration method at branding by $86 \%$ of veterinarians $(\mathrm{n}=132)$, banding was selected as the preferred method by $11 \%$ of veterinarians $(\mathrm{n}=114)$, burdizzo by $1 \%$ of veterinarians $(\mathrm{n}=73)$, and no castration of bull calves at branding was the preferred recommendation of $27 \%$ of veterinarians ( $\mathrm{n}$ $=22$ ) (Table 9). At weaning, knife cut was the preferred castration method recommended by $67 \%$ of veterinarians ( $\mathrm{n}=123$ ), banding was the second-most preferred castration method for $25 \%$ of veterinarians $(\mathrm{n}=106)$, burdizzo was the next most preferred castration method for $15 \%$ of veterinarians $(\mathrm{n}=65)$, and no castration of bull calves at weaning was the preferred recommendation of $61 \%$ of veterinarians $(\mathrm{n}=36)$ (Table 9$)$. In agreement with results from this survey, the USDA (2008a) reported that $49.2 \%$ of cow-calf operations in the United States used a surgical method when castrating calves, $47.3 \%$ preferred to use banding, and only $3.5 \%$ of operations preferred to use the burdizzo technique to castrate calves. Furthermore, Coetzee et al. (2010) reported that the most frequently used method of castration by the majority $(57 \%)$ of veterinarians was the surgical procedure, followed by the banding procedure, which was used by $44 \%$ of veterinarians.

Poor nutrition practices within the beef cow herd can have a significant negative effect on calf health in the following year after birth (Larson et al., 2004). Recommended nutrition management practices by veterinary practitioners are summarized in Table 10. Calf nutrition was considered as extremely important during a preconditioning program by $82 \%$ of responding veterinarians. The mineral status of the cow during prebreeding and lactation stages was considered as extremely important by $63 \%$ of responding veterinarians because it is related to long-term

Table 8. Descriptive data about production practices recommended by practicing cow-calf veterinarians in the United States and Canada

Item

Responses (no.) Responses (\%)

Genetic advice provided for clients $(n=147 ; 100 \%$ response rate)

Yes

79

No

Is low-stress handling techniques training recommended for all family members and employees ( $n=144 ; 98 \%$ response rate)

Yes

No

Other practices recommended at branding time $(n=119 ; 81 \%$ response rate)

Calfhood implant

Probiotics

Other practices recommended before weaning $(n=113 ; 77 \%$ response rate)

Calfhood implant

Other practices recommended after weaning ( $n=77 ; 52 \%$ response rate)

Calfhood implant

Probiotics

Is creep feeding regularly recommended to clients? $(n=144 ; 98 \%$ response rate)

Yes

No

Should calves be "bunk broke" (know how to eat from a feed bunk) before marketing? ( $\mathrm{n}$

$=144 ; 98 \%$ response rate)

Yes

No

Maybe $^{1}$

Is ear tag identification (used for sire and dam identification) for calves recommended?

( $n=146 ; 99 \%$ response rate)

Yes

No

68

54

46

119

25

89

65

43

1

58

86

78

54

14

52

10

36

101

69

${ }^{1}$ Depends on the situation and characteristics of each individual operation. 
Table 9. Descriptive data about castration method ranking and calf management practices recommended by practicing cowcalf veterinarians in the United States and Canada

\section{Item}

Responses (no.) Responses (\%)

Earliest age ever recommended for weaning calves due to weather conditions or other cultural practices deemed necessary $(n=143 ; 97 \%$ response rate)
31 to $60 \mathrm{~d}$
60 to $90 \mathrm{~d}$
90 to $120 \mathrm{~d}$
120 to $150 \mathrm{~d}$
$>150 \mathrm{~d}$

Type of weaning protocol recommended to clients ( $n=143 ; 97 \%$ response rate)

Recommended number of days weaned

Fence-line weaning

Abrupt drylot weaning or onto truck

Two-stage weaning with nose clips

Recommended age for castration of bull calves $(n=145 ; 99 \%$ response rate)

0 to $7 \mathrm{~d}$

$<1 \mathrm{mo}$

1 to $2 \mathrm{mo}$

2 to $3 \mathrm{mo}$

$>3$ mo

Branding

Other $^{1}$

Castration methods selected as best option for calves at branding time ${ }^{2}$

1. Knife cut

2. Banding

3. Burdizzo

4. Do not recommend

Castration methods selected as best option for calves at weaning ${ }^{3}$

1. Knife cut

2. Banding

3. Burdizzo

4. Do not recommend

$\begin{array}{rr}4 & 3 \\ 32 & 22 \\ 55 & 38 \\ 42 & 29 \\ 10 & 7\end{array}$

3

22

38

29

$91 \quad 64$

$82 \quad 57$

$15 \quad 10$

$12 \quad 8$

$48 \quad 34$

$5 \quad 4$

$21 \quad 15$

$26 \quad 18$

$8 \quad 6$

$22 \quad 16$

118

$113 \quad 86$

$12 \quad 11$

$1-1$

627

${ }^{1}$ Other: 2 to 4 mo; 2 wk before weaning; 181.4 to $226.8 \mathrm{~kg}$; soon as owner knows it will not be a breeding bull; spring (45.4 to $181.4 \mathrm{~kg}$ ); turn out; <136.1 kg; depends.

${ }^{2}$ Number and percentage of responses reported for each castration method represent the responses that selected each method as the best option: knife cut $(n=132)$, banding $(n=114)$, burdizzo $(n=73)$, do not recommend $(n=22)$.

${ }^{3}$ Number and percentage of responses reported for each castration method represent the responses that selected each method as the best option: knife cut $(n=123)$, banding $(n=106)$, burdizzo $(n=65)$, do not recommend $(n=36)$.

calf health. Comerford et al. (2013) recommended providing cows with a trace mineral supplement and a source of $\mathrm{Ca}, \mathrm{P}, \mathrm{Mg}$, and Se throughout the year. However, only $25 \%$ of veterinarians recommended to always supplement chelated minerals for the cow herd, although the majority $(61 \%)$ of veterinarians only recommended chelated minerals "sometimes." Injectable vitamins for the breeding herd were not recommended by $55 \%$ of veterinary practitioners (Table 10).

\section{IMPLICATIONS}

It is of upmost importance to the authors to highlight the limitations of survey data presented in this paper. This survey reports recommendations currently made by a por- tion of the consulting veterinarians and practitioners that service cow-calf operations. The practices and recommendations reported in this survey may change over time due to a variety of factors. Reporting summaries of practices and recommendations made by consulting veterinarians provides a benchmark for standard operating procedures used in the beef cattle industry, and the summaries are useful resources for the industry and the scientific-academic community.

\section{ACKNOWLEDGMENTS}

This project was funded by the Red Angus Association of America and Kansas State University Agricultural Experiment Station. 
Table 10. Descriptive data about nutrition management practices for the cow-calf herd made by practicing veterinarians in the United States and Canada

Item

Responses (no.) Responses (\%)

How important is nutrition for the calf during a preconditioning program or weaning? ( $\mathrm{n}$

$=146 ; 99 \%$ response rate)

Extremely important

Very important

Important

How important is mineral status of the cow (prebreeding and lactation) in relation to

long-term calf health? ( $n=146 ; 99 \%$ response rate)

Extremely important

Very important

Important

Somewhat important

Are chelated minerals recommended for the cow herd? $(n=146 ; 99 \%$ response rate)

Yes, always

Sometimes

Never

Are injectable vitamins recommended for the breeding herd? ( $n=145$; 99 response

rate)

Yes

No

$\begin{array}{rr}119 & 82 \\ 25 & 17 \\ 2 & 1 \\ & \\ 92 & 63 \\ 38 & 26 \\ 13 & 9 \\ 3 & 2 \\ & \\ 36 & 25 \\ 89 & 61 \\ 21 & 14 \\ & \\ 65 & 45 \\ 80 & 55\end{array}$

\section{LITERATURE CITED}

AVMA. 2014. Literature Review on the Welfare Implications of Castration of Cattle. Am. Vet. Med. Assoc. Anim. Welf. Div., Schaumburg, IL.

Bolte, J. W., K. C., Olson, J. R. Jaeger, T. B. Schmidt, D. U. Thomson, B. J. White, R. L. Larson, N. A. Sproul, L. A. Pacheco, and M. D. Thomas. 2009. Length of the weaning period affects postweaning growth, health, and carcass merit of ranch-direct beef calves weaned during the fall. Cattlemen's Day. Kansas State Univ., Manhattan.

Bretschneider, G. 2005. Effects of age and method of castration on performance and stress response of beef male cattle: A review. Livest. Prod. Sci. 97:89-100.

Coetzee, J. F., A. L. Nutsch, L. A. Barbur, and R. M. Bradburn. 2010. A survey of castration methods and associated livestock management practices performed by bovine veterinarians in the United States. BMC Vet. Res. 6:12.

Cole, N. A., J. B. McLaren, and M. R. Irwin. 1979. Influence of pretransit feeding regimen and post-transit B-vitamin supplementation on stressed feeder steers. J. Anim. Sci. 49:310-317.

Comerford, J. W., G. L. Greaser, H. L. Moore, and J. K. Harper. 2013. Beef Cow-Calf Production. Agricultural Alternatives. Penn State Coop. Ext., The Pennsylvania State Univ., University Park.

Faulkner, D. B., T. Eurell, W. J. Tranquilli, R. S. Ott, M. W. Ohl, G. F. Cmarik, and G. Zinn. 1992. Performance and health of weanling bulls after butorphanol and xylazine administration at castration. J. Anim. Sci. 70:2970-2974.

Galyean, M. L. 1996. Protein levels in beef cattle finishing diets: Industry application, university research, and systems results. J. Anim. Sci. 74:2860-2870.

Galyean, M. L., and J. F. Gleghorn. 2001. Summary of the 2000 Texas Tech University Consulting Nutritionist Survey. Texas Tech Univ., Dept. Anim. Food Sci., Burnett Center Internet Progress Report No.
12. Accessed Apr. 26, 2017. http://www.asft.ttu.edu/burnett_center/ progress_reports/ bc12.pdf.

Gonzalez, L. A., K. S. Schwartskopf-Genswein, N. A. Caulkett, E. Janzen, T. A. McAllister, E. Fierheller, A. L. Schaefer, D. B. Haley, J. M. Stookey, and S. Hendrick. 2010. Pain mitigation after band castration of beef calves and its effects on performance, behavior, Escherichia coli, and salivary cortisol. J. Anim. Sci. 88:802-810.

Kirkpatrick, J. G., D. L. Step, M. E. Payton, J. B. Richards, L. F. McTague, J. T. Saliki, A. W. Confer, B. J. Cook, S. H. Ingram, and J. C. Wright. 2008. Effect of age at the time of vaccination on antibody titers and feedlot performance in beef calves. J. Am. Vet. Med. Assoc. 233:136-142.

Larson, R. L., J. W. Tyler, L. G. Schultz, R. K. Tessman, and D. E. Hostetler. 2004. Management strategies to decrease calf death losses in beef herds. J. Am. Vet. Med. Assoc. 224:42-48.

Lee, T. L., S. P. Terrell, S. J. Bartle, C. D. Reinhardt, M. D. Apley, D. Rethorst, and D. U. Thomson. 2015. Current feedlot cattle health and well-being program recommendations in the United States and Canada: The 2014 feedlot veterinary consultant survey. Bov. Pract. 49:124-131.

Macartney, J. E., K. G. Bateman, and C. S. Ribble. 2003. Health performance of feeder calves sold at conventional auctions versus special auctions of vaccinated or conditioned calves in Ontario. J. Am. Vet. Med. Assoc. 223:677-683.

NCBA. 2015. Directions Statistics. National Cattlemen. 29th ed. Natl. Cattlemen's Beef Assoc., Centennial, CO.

Peterson, E. B., D. R. Strohbehn, G. W. Ladd, and R. L. Willham. 1989. Effects of preconditioning on performance of beef calves before and after entering the feedlot. J. Anim. Sci. 67:1678-1686.

Radostits, O. M., K. E. Leslie, and J. Fetrow. 1994. Planned animal health and production in beef cattle breeding. Pages 331-393 in Herd Health: Food Animal Production Medicine. 2nd ed. WB Saunders Co., Philadelphia, PA. 
Roeber, D. L., N. C. Speer, J. G. Gentry, J. D. Tatum, C. D. Smith, J. C. Whittier, G. F. Jones, K. E. Belk, and G. C. Smith. 2001. Feeder cattle health management: Effects on morbidity rates, feedlot performance, carcass characteristics, and beef palatability. Prof. Anim. Sci. $17: 39-44$.

Rust, R. L., D. U. Thomson, G. H. Loneragan, M. D. Apley, and J. C. Swanson. 2007. Effect of different castration methods on growth performance and behavior responses of postpubertal beef bulls. Bov. Pract. 41:111-118.

Samuelson, K. L., M. E. Hubbert, M. L. Galyean, and C. A. Löest. 2016. Nutritional recommendations of feedlot consulting nutritionists: The 2015 New Mexico State and Texas Tech University survey. J. Anim. Sci. 94:2648-2663.

Sanderson, M. W., D. A. Dargatz, and F. B. Garry. 2000. Biosecurity practices of beef cow-calf producers. J. Am. Vet. Med. Assoc. 217:185-189.

Terrell, S. P., D. U. Thomson, C. D. Reinhardt, M. D. Apley, C. K. Larson, and K. R. Stackhouse-Lawson. 2014. Perception of lameness management, education, and effects on animal welfare of feedlot cattle by consulting nutritionists, veterinarians, and feedlot managers. Bov. Pract. 48:53-60.

Terrell, S. P., D. U. Thomson, B. W. Wileman, and M. D. Apley. 2011. A survey to describe current feeder cattle health and well-being program recommendations made by feedlot veterinary consultants in the United States and Canada. Bov. Pract. 45:140-148.

USDA. 2008a. Beef 2007-8. Part I: Reference of Beef Cow-Calf Management Practices in the United States, 2007-08. \#N512-1008. USDA-Anim. Plant Health Inspect. Serv.-Vet. Serv., Ctr. Epidemiol. Anim. Health, Fort Collins, CO.

USDA. 2008b. Beef 2007-08. Part III: Changes in the US Beef CowCalf Industry, 1993-2008. \#518.0509. USDA-Anim. Plant Health Inspect. Serv.-Vet. Serv., Ctr. Epidemiol. Anim. Health, Fort Collins, CO.
USDA. 2010. Beef 2007-08. Part IV: Reference of Beef Cow-Calf Management Practices in the United States, 2007-08. \#523.0210. USDAAnim. Plant Health Inspect. Serv.-Vet. Serv., Ctr. Epidemiol. Anim. Health, Fort Collins, CO.

USDA. 2014. 2012 Census of Agriculture. United States Summary and State Data. Vol. 1, Geographic Area Series, Part 51. AC-12-A-51. USDA, Natl. Agric. Stat. Serv., Washington, DC.

USDA. 2015. Agricultural Statistics 2015. USDA, Natl. Agric. Stat. Serv., United States Gov. Print. Off., Washington, DC.

USDA. 2017a. Livestock Slaughter 2016 Summary (April 2017). USDA, Natl. Agric. Stat. Serv., Washington, DC.

USDA. 2017b. United States and Canadian Cattle and Sheep (March 2017). USDA, Natl. Agric. Stat. Serv., Washington, DC.

USDA. 2017c. Cattle (January 2017). USDA, Natl. Agric. Stat. Serv., Washington, DC.

Vasconcelos, J. T., and M. L. Galyean. 2007. Nutritional recommendations of feedlot consulting nutritionists: The 2007 Texas Tech University survey. J. Anim. Sci. 85:2772-2781.

Waldner, C., M. D. Jelinski, and K. McIntyre-Zimmer. 2013. Survey of western Canadian beef producers regarding calf-hood diseases, management practices, and veterinary service usage. Can. Vet. J. 54:559-564.

Woolums, A. R., R. D. Berghaus, D. R. Smith, B. J. White, T. J. Engelken, M. B. Irsik, D. K. Matlick, A. L. Jones, R. W. Ellis, I. J. Smith, G. L. Mason, and E. R. Waggoner. 2013. Producer survey of herd-level risk factors for nursing beef calf respiratory disease. J. Am. Vet. Med. Assoc. 243:538-547.

Woolums, A. R., R. D. Berghaus, D. R. Smith, B. J. White, T. J. Engelken, M. B. Irsik, D. K. Matlik, A. L. Jones, and I. J. Smith. 2014. A survey of veterinarians in 6 US states regarding their experience with nursing beef calf respiratory disease. Bov. Pract. 48:26-35. 